\title{
Beyond winning: mediation, conflict resolution, and non-rational sources of conflict in the ICU
}

\author{
Kerry Knickle', Nancy McNaughton ${ }^{1}$ and James Downar ${ }^{* 2,3}$
}

\begin{abstract}
A 55-year-old woman with widely metastatic breast cancer was admitted to your intensive care unit (ICU) because of a decreased level of consciousness and respiratory failure. She had documented cerebral and meningeal metastases that were progressing despite chemotherapy and radiotherapy. The admitting physician met with her family and suggested a palliative approach, making them very upset. The family insisted that the team 'do everything' and now they refuse to discuss any change in the plan of treatment. They maintain a constant presence at the bedside, taking notes and questioning everyone who enters the room. They have threatened legal action toward several of the nursing staff, and hospital security has been called twice because of shouting matches between family and staff members. As the physician taking over care for the ICU, you would like to resolve this conflict.
\end{abstract}

\section{Introduction}

Conflict is a common occurrence in intensive care units (ICUs) [1,2]. ICU workers and family members must interpret large amounts of information to make difficult decisions for incapable patients with life-threatening illnesses. Experts recommend a model of 'shared decisionmaking, which aims to achieve a consensus among the patient, family, and health-care team about goals of care [3-5]. But consensus is not always achieved; a physician may adopt a paternalistic model of decision-making, and some family members may not value the opinions of the physician [6]. Disagreements are common and can easily escalate $[7,8]$, as they have in this case. Conflicts may occur within the health-care team or with family members [1], resulting in potentially severe consequences

*Correspondence: james.downar@utoronto.ca

2Divisions of Critical Care/Respirology and Palliative Care, University Health

Network, 200 Elizabeth Street, 9N-926, Toronto, ON, M5G 2C4, Canada

Full list of author information is available at the end of the article for patients, family members, and health-care workers alike $[1,9]$. Few clinicians have any formal training in mediation or conflict resolution.

Conflict is not unique to the ICU environment, and other professions have developed approaches to resolving disagreements that have escalated into conflict. In this article, we will review key principles of mediation and explain how they can be applied in the ICU setting.

\section{Conflict and mediation}

1. How does conflict start? Naming, blaming, and claiming

A line in the sand has been drawn, and there is an angry standoff. How did we get here? Two people may not agree on a particular decision, but that does not necessarily lead to a conflict. Conflicts are usually a product of an additional element - something that people think or feel but do not say directly. Any individuals who work or live together can experience thoughts or feelings of hurt, loss, betrayal, guilt, or anger toward one another at some point. The very nature of conflict is described as 'subjective, unstable, reactive, complicated and incomplete' [10], but disagreement or tension between people does not always lead to conflict.

Conflicts generally develop by a process of naming, blaming, and claiming. Naming occurs when an individual perceives a situation as injurious. Blaming transpires when the individual identifies other parties in the injurious event. Finally, claiming occurs when the individual seeks out the party or organization responsible for remedy or restitution [11].

\section{Mediation: positions versus interests}

The scholarly field and professional practice of conflict resolution emerged after World War II [12]. The conflict continuum includes negotiation, mediation, arbitration, and litigation as a spectrum of third-party dispute resolution practices. Mediation is a popular conflict resolution process used widely across professional organizations.

Mediation is described by legal scholars as a facilitated process designed to resolve conflict between two parties in a voluntary and mutually acceptable way through neutral third-party assistance as an alternative to proceedings that are more coercive (for example, arbitration 
and litigation). Whereas some disagreements can be resolved by the disputants themselves, other situations benefit from third-party intervention. Third-party mediation may be required when conflicts feature intense emotion, poor communication, misperceptions, repetitive negative behaviors, disagreement over data, prioritization of multiple issues, and perceived or real incompatible interests between the disputants [13].

The mediator is a key figure in the role of compassionate, authentic, and responsible transmitter between and advocate for two or more parties. The mediator role also includes the following [14]: participating in constructing the problem, reframing and relabeling the problem, reordering the sequence of the plot elements, and remaking history by altering stories and creating the future by building new stories.

Stephen Littlejohn, conflict management consultant, writes: 'Instead of settling a dispute, we need to think of ways to transform it. Instead of encapsulating a conflict, we need to think of ways to redefine it' [15]. Mediation is a forum for parties to create a new and shared understanding of their positions and interests. Positions are best described as the entrenched ideas that one party holds about the relationship, process, or substance of a conflict (what I want). Interests are the reasons behind the positions being held (why I want what I want). The mediator focuses on helping the parties explore their underlying interests rather than focus on their positions, to talk less about what they want and more about why they want it. For example, in a common conflict between a parent and child, a mediator might elicit the following positions and interests:

Parental position: 'I want my 13-year-old child in the house at 9 p.m.'

Parental interest: 'I want to be sure that my child is safe'.

Child position: 'I do not want to come home at 9 p.m.'

Child interest: 'I believe I am old enough to decide when to come home'.

\section{Emotion: a barrier and a catalyst in conflict resolution}

Emotion is a central feature of any conflict, and conflicts are often seen as irrational on the basis of the emotional sense of indignation or outrage of each party. People tend to think in terms of reason and logic versus emotion. They isolate reason from emotion in their analysis of conflict and decision-making, when in fact the two are more deeply connected.

Anger is the cardinal emotion attached to conflict. Anger is frequently seen as a barrier to our ability to reason and think objectively. However, emotion is fundamentally connected to our reasoning skills and cognition and can be an important source of feedback. Antonio Damasio, a neuroscientist, writes: 'When emotion is entirely left out of the reasoning picture... reason turns out to be even more flawed than when emotion plays bad tricks on our decisions' [16].

Emotion can be a direct source of strength and energy. For example, anger can mobilize individuals or groups as a productive force toward change (for example, the civil rights and women's rights movements). However, the expression of emotion can be counterproductive or destructive, wounding others.

Emotions are contagious. In the presence of anger, it is important to discern a signal for change or a struggle for power. How we express emotion has implications for mediation and conflict resolution processes and outcomes. Our ability to acknowledge our emotion in the midst of conflict increases our capacity for "reflection-inaction" - the ability to combine cognitive and emotional information in the moment [17]. This ability can be harnessed to produce alliances around a common issue.

\section{Mediation: process and function}

The mediation process aims to achieve a mutually acceptable solution respecting the self-determination of all parties. Thus, skilled mediators emphasize problem solving, impartiality, fairness, ethical awareness, analytical skills, empathy, and a strong sense of self [18]. For those interested in pursing mediation, these skills and abilities are an important addition to the professional toolbox.

The role of the mediator involves the following: introducing mediation as a voluntary process, establishing ground rules for the conversation, ensuring confidentiality for all parties, encouraging all parties to fully tell their story from their perspective, allowing parties to gain a shared perspective through listening and retelling and clarification, brainstorming options in order to generate a mutually agreed-upon resolution, and facilitating the parties' co-creation and consensus of a mutual agreement or contract (legal to non-binding) as a blueprint for future action.

Within the process, mediator skills and techniques include helping the parties to do the following: stay focused on the issues, set aside the desire to 'win', focus on joint problem solving, suspend blame and judgment, strive for neutrality, clarify assumptions, find common ground, use straightforward language, and apologize if appropriate.

Successful outcomes are shaped by the skills and abilities of experienced mediators. Macfarlane [10] suggests that active listening may be the most important skill for any mediator or third-party intervener. Active listening skills include acknowledging, paraphrasing, reflecting, clarifying, questioning, and summarizing as well as using non-verbal communication skills (Table 1). These are effective skills to consider in daily practice with friends, family, and coworkers [19]. 


\section{Mediating conflict as a physician in a dyad or triad} The complex mélange of competencies required of the skilled mediator implies a high degree of personal and professional self-awareness and investment in promoting effective interaction with others. Can medical professionals learn to equip themselves with these critical interpersonal skills in order to independently manage their own conflicts or potential third-party interventions? What would be the consequence of integrating the tenets, skills, and techniques of mediation into daily personal and professional practice? As linguist Deborah Tannen writes: 'The terms in which we talk about something shape the way we think about it - and even what we see' [20]. Whether happy, frustrated, conflicted, or misunderstood, we are simultaneously constructing and constructed by what we say and how we say it.

Every conflict requires a unique solution because of the unique characteristics of each participant, but we can hone our mediation skills with practice. Whether we are participating as a mediator in a triad or as a member of a dyad with colleagues, friends, clients, or family members, we need to build a capacity and trust in our own mediation skills. The principles of mediation and effective communication may not only foster individual resilience in approaching and addressing personal and professional conflict issues but also build confidence and competence in productive interactions and have important implications for stronger communities of practice. In short, ICU clinicians could benefit from learning and employing basic mediation skills in the ICU environment to further therapeutic and collegial relationships regardless of whether conflict exists.

\section{Applying mediation to intensive care unit conflict}

The present case is a typical but extreme example of a conflict between family members and the health-care team. When approaching this conflict, you may try to become involved as a neutral third-party mediator, but this role would be difficult to fulfill as a member of a health-care team. You could attempt a resolution yourself in a dyadic model (as is usually the case in the ICU), or you may engage a third-party mediator because of the emotions or perceived incompatibility of the interests of the parties (or other considerations mentioned above). In some jurisdictions, a third-party mediator is mandated by law or policy in any case involving withdrawal or withholding of life-sustaining treatment [21]. Of course, formal third-party mediation can be costly and timeconsuming, which would limit its widespread use.

The choice of mediator is important. The medical team may opt for a mediator who is experienced in medical matters, but the patient/family may not feel that this person is truly neutral. A hospital bioethicist is sometimes called upon to mediate disputes, but this person has a potential conflict of interest as a hospital employee.
In Ontario, Canada, a neutral panel known as the Consent and Capacity Board is often convened to mediate disputes about patient care [22]. This panel can be convened in a matter of days at no cost to the participants. Similar panels exist in other jurisdictions.

The Consent and Capacity Board is rarely convened for ICU cases but, in our experience, has served as an effective third-party mediator in cases in which the family and the health-care team had fallen into a pattern of repetitive negative behaviors or in cases in which there was a perceived incompatibility of interests. The board consists of three members, two of whom are nonphysicians. The head of the board, a lawyer with training in mediation, has resolved cases simply by clarifying the role of a surrogate decision-maker or by clarifying the interests of the two parties (rather than the positions) and demonstrating that they were not incompatible. Anecdotally, this core mediation skill has been particularly effective for resolving ICU cases. In other situations, even the full process of a board hearing was not sufficient to create agreement between the parties, and a more coercive process was required (for example, applications to the courts). However, members of the health-care team and the family often take comfort from the process, as it leads to an improved understanding about the interests and motivations of the other party [23].

To proceed with mediation, you will need to ensure that the family is willing to participate in the process. If they are not willing, mediation will not be successful, and you may need to pursue proceedings that are more coercive in order to resolve the conflict. If the family members agree to mediation in a dyadic model, you will need to internalize the role of the mediator and attempt to determine their positions and interests while recognizing and expressing your own. Work toward reframing the conflict in a way that achieves a new understanding for both parties.

A patient or family request for 'everything' is a position you need to find the interests behind that position. Quill and colleagues [24] have suggested some potential interests and useful approaches for exploring them. Start by exploring the conflict from the family's perspective (in particular, why they were so upset by the suggestion of palliative care and why they do not want to discuss any change in the plan of treatment). Possible 'interests' and questions for this family might include the following:

- A need to complete specific life goals or see family members ("What things did she want to achieve before she became ill?')

- A need to be certain that all legitimate treatment options have been exhausted ('What have others told you about the status and prognosis of her disease?')

- A need to help the patient's children and spouse come to terms with her anticipated death ('What do her children understand about her illness?') 
Table 1. Active listening skills and techniques for conflict resolution [27]

\begin{tabular}{|c|c|c|}
\hline Technique/Skill & Function & Example \\
\hline \multirow[t]{2}{*}{$\begin{array}{l}\text { Validating: support and acknowledgement of } \\
\text { the parties'feelings }\end{array}$} & $\begin{array}{l}\text { Acknowledges the feeling of hurt and conveys respect and } \\
\text { acceptance }\end{array}$ & \multirow[t]{2}{*}{$\begin{array}{l}\text { 'You're feeling overwhelmed by having to } \\
\text { make these decisions... where do you begin? }\end{array}$} \\
\hline & Allows understanding of feelings and other perspectives & \\
\hline \multirow{3}{*}{$\begin{array}{l}\text { Reflecting (in the form of a question): } \\
\text { checking in and interpreting what you have } \\
\text { heard }\end{array}$} & $\begin{array}{l}\text { Similar to clarifying, reflecting provides an opening for a richer } \\
\text { and more thorough response }\end{array}$ & \multirow{3}{*}{$\begin{array}{l}\text { 'You're feeling like your efforts aren't being } \\
\text { recognized or respected by the intensive care } \\
\text { unit staff or by me... am I accurate?' }\end{array}$} \\
\hline & Allow an opportunity to expand upon and clarify a perspective & \\
\hline & An opportunity to confirm and acknowledge feelings & \\
\hline \multirow{3}{*}{$\begin{array}{l}\text { Paraphrasing: using your own words to } \\
\text { interpret your colleagues'thoughts and } \\
\text { feelings }\end{array}$} & $\begin{array}{l}\text { Lets the speaker know that you hear the message they are } \\
\text { sending }\end{array}$ & \multirow[t]{3}{*}{$\begin{array}{l}\text { 'You feel like we have been disrespectful and } \\
\text { neglectful in your mother's care'. }\end{array}$} \\
\hline & Gives the receiver (perceiver) the same opportunity & \\
\hline & Slows down the pace of the conversation & \\
\hline \multirow{6}{*}{$\begin{array}{l}\text { Questioning: appropriate use of open- and } \\
\text { close-ended questions }\end{array}$} & Opens up discussion & \multirow{2}{*}{$\begin{array}{l}\text { Open: 'Can you help me understand more } \\
\text { about...?' }\end{array}$} \\
\hline & Allows exchange of information & \\
\hline & Encourages expression & \multirow[t]{4}{*}{ Closed: 'When did you decide to...?' } \\
\hline & Obtains information about facts and feelings & \\
\hline & Confirms understanding & \\
\hline & Provides insight about who, what, where, why, and how & \\
\hline \multirow{2}{*}{$\begin{array}{l}\text { Clarifying: checking to verify facts, } \\
\text { information, or feelings that have been } \\
\text { expressed }\end{array}$} & Proof positive that you are listening closely & \multirow{2}{*}{$\begin{array}{l}\text { 'You're finding this hard because you're not } \\
\text { sure if it's what your mother would have } \\
\text { really wanted... Would that be fair to say?' }\end{array}$} \\
\hline & Helps elucidate or disarm conflict issues & \\
\hline \multirow{4}{*}{$\begin{array}{l}\text { Summarizing: brief verbal reviews } \\
\text { throughout your conversation and a final } \\
\text { summary moving to settlement }\end{array}$} & $\begin{array}{l}\text { Helps to maintain a mutual and accurate understanding of } \\
\text { facts, interests, needs, and positions }\end{array}$ & \multirow{4}{*}{$\begin{array}{l}\text { 'You think we don't respect your efforts and } \\
\text { goals, so you have been unwilling to engage } \\
\text { in any more discussion with us'. }\end{array}$} \\
\hline & Keeps the discussion on track (that is, 'where we are') & \\
\hline & Helps focus the parties & \\
\hline & $\begin{array}{l}\text { A final summary of your mutual agreement enhances the } \\
\text { resolution process }\end{array}$ & \\
\hline
\end{tabular}

- A need to respect God's role in deciding matters of life and death ('How would we know when it is her time to pass on?')

There are likely to be issues of misperception and lack of trust. These questions are intended as starting points for a discussion, but ongoing use of active listening skills will be key to achieving a better understanding of the family's interests.

Next, you will need to help the family explore not only the interests of the health-care team in suggesting palliative care but also any other incident that may have upset the family. Pantilat [25] has suggested useful and compassionate phrases that can help in such interactions. Typically, the health-care team suggests a transition to palliative care out of a desire to avoid therapies that they feel are non-beneficial and potentially uncomfortable. This is often communicated (or heard) as 'stopping everything' or 'withdrawing care', which is inaccurate and upsetting. Getting family members to ask exploratory questions may be difficult and require prompting. It may be helpful to start by explaining this interest explicitly from your perspective (similar to how the family has explained their interest) and discuss how you feel that the present (or proposed) management plan does not achieve that interest. The family must feel empowered to ask questions and seek a greater understanding of the healthcare team's perspective. This is a critical element in the process of achieving a new and shared perspective between both parties.

During the process of exploration and understanding, you will also need to address the anger that has characterized this dispute. As explained above, anger and emotion are not the enemies of rational thought and conflict resolution. They are common responses in the ICU and indicate the high degree of importance that all parties attach to decisions that are made here. It may be helpful to start with a validation of the emotions displayed (for example, 'I can certainly see how much you care about your loved one and the treatments she receives') but try to agree on some ground rules to prevent any eruptions during the mediation process (for example, no interrupting, no raised voices, and no 
personal attacks). Participants should be encouraged to express their concerns in a non-confrontational way by using 'I feel' statements (for example, 'I feel that I am not helping your wife' rather than 'You are torturing your wife'). All parties need to recognize that emotions are valid but must be expressed in an appropriate way.

During the process of mediation, it is easy to fall back into the familiar behaviors that led to the conflict in the first place. As a mediator, you must recognize certain cardinal symptoms of conflict (for example, escalation, repetition, and focusing on disputed data). When you observe these symptoms, you should reframe the discussion, focus on areas of common ground, and help the parties generate potential solutions to perceived problems. Often, the interests of the family may be served by non-medical interventions (for example, spiritual care, second opinions, and bereavement counseling), and physicians should recognize that end-of-life care in the ICU is not uniform [26]. It may be possible to acknowledge the interests of the family and the healthcare team and move beyond the positions of both parties.

Ultimately, you may require multiple sessions to achieve a mediated solution to this conflict, or in some cases you may not achieve a solution at all. But if you are able to participate in a dialogue that leads to a better mutual understanding and joint problem solving, the conflict will certainly de-escalate and a resolution will be easier to achieve.

\section{Conclusions}

Disagreements are common in the ICU and can easily escalate into conflicts that have serious consequences for patients, family members, and health-care workers. Conflict resolution skills are therefore an important competency for any ICU professional. By using active listening skills and understanding interests rather than positions, ICU workers can help to achieve a shared understanding among parties in conflict.

\section{Abbreviation}

ICU, intensive care unit.

\section{Competing interests}

The authors declare that they have no competing interests.

\section{Author details}

'Standardized Patient Program, Faculty of Medicine, University of Toronto, 88 College Street, Toronto, ON, M5G 1L4, Canada. ${ }^{2}$ Divisions of Critical Care/ Respirology and Palliative Care, University Health Network, 200 Elizabeth Street, 9N-926, Toronto, ON, M5G 2C4, Canada. ${ }^{3}$ University Health Network, 190 Elizabeth Street, Toronto, ON, M5G 2C4, Canada.

Published: 19 June 2012

\section{References}

1. Azoulay E, Timsit JF, Sprung CL, Soares M, Rusinová K, Lafabrie A, Abizanda $R$, Svantesson M, Rubulotta F, Ricou B, Benoit D, Heyland D, Joynt G, Français A, Azeivedo-Maia P, Owczuk R, Benbenishty J, de Vita M, Valentin A, Ksomos A, Cohen S, Kompan L, Ho K, Abroug F, Kaarlola A, Gerlach H, Kyprianou T, Michalsen A, Chevret S, Schlemmer B, et al.: Prevalence and factors of intensive care unit conflicts: the conflicus study. Am J Respir Crit Care Med
2009, 180:853-860

2. Breen CM, Abernethy AP, Abbott KH, Tulsky JA: Conflict associated with decisions to limit life-sustaining treatment in intensive care units. J Gen Intern Med 2001, 16:283-289.

3. Truog RD, Campbell ML, Curtis JR, Haas CE, Luce JM, Rubenfeld GD, Rushton $\mathrm{CH}$, Kaufman DC: Recommendations for end-of-life care in the intensive care unit: a consensus statement by the American Academy of Critical Care Medicine. Crit Care Med 2008, 36:953-963.

4. Curtis JR, White DB: Practical guidance for evidence-based ICU family conferences. Chest 2008, 134:835-843.

5. Davidson JE, Powers K, Hedayat KM, Tieszen M, Kon AA, Shepard E, Spuhler V, Todres ID, Levy M, Barr J, Ghandi R, Hirsch G, Armstrong D; American College of Critical Care Medicine Task Force 2004-2005, Society of Critical Care Medicine: Clinical practice guidelines for support of the family in the patient-centered intensive care unit: American College of Critical Care Medicine Task Force 2004-2005. Crit Care Med 2007, 35:605-622.

6. Heyland DK, Cook DJ, Rocker GM, Dodek PM, Kutsogiannis DJ, Peters S, Tranmer JE, O'Callaghan CJ: Decision-making in the ICU: perspectives of the substitute decision-maker. Intensive Care Med 2003, 29:75-82.

7. Golubchukv. Salvation Army Grace General Hospital et al., 2008 MBQB 49.

8. Rasouli v. Sunnybrook Health Sciences Centre, 2011 ONCA 482.

9. Fassier T, Azoulay E: Conflicts and communication gaps in the intensive care unit. Curr Opin Crit Care 2010, 16:654-665.

10. Macfarlane J: Dispute Resolution: Readings and Case Studies. 2nd edition. Toronto, ON: Emond Montgomery Publications; 2003.

11. Felstiner $W$, Abel $R$, Sarat $A$ : The emergence and transformation of disputes: naming, blaming and claiming. In Dispute Resolution: Readings and Case Studies. 2nd edition. Edited by Macfarlane J. Toronto, ON: Emond Montgomery Publications Inc:; 2003:2-3.

12. Deutsch M, Coleman PT: Preface. In The Handbook of Conflict Resolution: Theory and Practice. Edited by Deutsch M. San Francisco, CA: Jossey-Bass; 2000:xi.

13. Moore C: The Mediation Process: Practical Strategies for Resolving Conflict. San Francisco, CA: Jossey-Bass; 1996.

14. Cobb S: Einsteinian practice and newtonian discourse: an ethical crisis in mediation. Negotiation Journal 1991:87-102.

15. Littlejohn S: The Transcendent Communication Project: searching for a praxis of dialogue. Conflict Resolution Quarterly 2004, 21:337-359.

16. Damasio A: Descartes Error: Emotion, Reason and the Human Brain. New York: G.P. Putnam; 1994

17. Schon D: The Reflective Practitioner: How Professionals Think in Action. New York: Basic Books Inc.; 1983.

18. Benjamin R: Managing the natural energy of conflict. In Bringing Peace into the Room: How the Personal Qualities of the Mediator Impact the Process of Conflict Resolution. Edited by Bowling D, Hoffman D. San Francisco, CA: Jossey-Bass; 2003:92,109,111,112.

19. LeBaron M, Robinson V: Conflict Analysis and Resolution as Education: Culturally Sensitive Processes for Conflict Resolution. Victoria, BC: University of Victoria Institute for Dispute Resolution; 2004.

20. Tannen D: The Argument Culture: Stopping America's War of Words. New York: Ballantine Books; 1998.

21. Romano ME, Wahlander SB, Lang BH, Li G, Prager KM: Mandatory ethics consultation policy. Mayo Clin Proc 2009, 84:581-585.

22. Consent and Capacity Board Website [http://www.ccboard.on.ca/scripts/ english/aboutus/index.asp].

23. Chidwick P, Sibbald R: Physician perspectives on legal processes for resolving end-of-life disputes. Healthc Q 2011, 14:69-74.

24. Quill TE, Arnold R, Back AL: Discussing treatment preferences with patients who want 'everything'. Ann Intern Med 2009, 151:345-349.

25. Pantilat SZ: Communicating with seriously ill patients: better words to say. JAMA 2009, 301:1279-1281.

26. Prendergast TJ, Claessens MT, Luce JM: A national survey of end-of-life care for critically ill patients. Am J Respir Crit Care Med 1998, 158:1163-1167.

27. Knickle K, McNaughton N: Communication Skills and Techniques for Conflict Resolution. Toronto, Canada: Standardized Patient Program, University of Toronto; 2007 [http://www.spp.utoronto.ca/images/stories/Resources/comm_ skills_techniq_conflict_resol_2007.pdf].

doi:10.1186/cc11141

Cite this article as: Knickle K, et al:: Beyond winning: mediation, conflict resolution, and non-rational sources of conflict in the ICU. Critical Care 2012, 16:308. 